\title{
Serum Caveolin-1 as a Novel Biomarker in Idiopathic Pulmonary Artery Hypertension
}

\author{
Kuo-Yang Wang, ${ }^{1,2,3}$ Mey-Fann Lee, ${ }^{4}$ Hung-Chin Ho, ${ }^{1,5}$ Kae-Woei Liang, ${ }^{1,6,7}$ Chia-Chi Liu, ${ }^{1,8}$ \\ Wan-Jane Tsai, ${ }^{1}$ and Wei-Wen Lin $^{1,3,5}$ \\ ${ }^{1}$ Cardiovascular Center, Taichung Veterans General Hospital, Taichung, Taiwan \\ ${ }^{2}$ School of Medicine, Chung Shan Medical University, Taichung, Taiwan \\ ${ }^{3}$ School of Medicine, China Medical University, Taichung, Taiwan \\ ${ }^{4}$ Department of Education and Research, Taichung Veterans General Hospital, Taichung, Taiwan \\ ${ }^{5}$ Department of Life Science, Tunghai University, Taichung, Taiwan \\ ${ }^{6}$ Institute of Clinical Medicine, Cardiovascular Research Center, Taiwan \\ ${ }^{7}$ Department of Medicine, National Yang Ming University School of Medicine, Taipei, Taiwan \\ ${ }^{8}$ Department of Biomedical Engineering \& Environmental Sciences, National Tsing Hua University, Hsinchu, Taiwan
}

Correspondence should be addressed to Wei-Wen Lin; weinlin@vghtc.gov.tw

Received 22 June 2015; Revised 16 August 2015; Accepted 18 August 2015

Academic Editor: Renzhi Han

Copyright (C) 2015 Kuo-Yang Wang et al. This is an open access article distributed under the Creative Commons Attribution License, which permits unrestricted use, distribution, and reproduction in any medium, provided the original work is properly cited.

\begin{abstract}
Pulmonary arterial hypertension (PAH) is a rare disease but with significant morbidity and high mortality. There is no specific way to diagnose PAH. Thus, an easy used with good sensitivity and specificity biomarker of PAH is highly desirable to aid in the screening, diagnosis, and follow-up. Caveolin-1 (Cavl) is the structural protein of caveolae and is highly expressed in type I pneumocytes. Lungs tissues from idiopathic PAH (IPAH) patients showed decreased expression of Cavl in vascular endothelial cells. Therefore, we developed a direct sandwich immunoassay for the determination of Cavl in IAPH patient's serum. The result disclosed serum Cavl level was significantly lower in IPAH than control groups. Using serum Cavl, $17.17 \mathrm{pg} / \mathrm{mL}$ as a cutoff value, the sensitivity was 0.59 and the specificity was 1.0. There were two major findings in our results. First, serum Cavl might be a novel biomarker in the diagnosis of IPAH with fare sensitivity and good specificity. Second, Cavl might be used to make differential diagnosis between COPD-PH and IPAH group.
\end{abstract}

\section{Introduction}

Pulmonary arterial hypertension $(\mathrm{PAH})$ is a rare disease but with significant morbidity and high mortality. Annual incidence is 1-2 cases per million people in the USA and it is $2-4$ times as common in women as in men $[1,2]$. In untreated patients, the median survival rate is only 2.8 years, and the 5 -year survival rate is $34 \%$ [3]. There is no specific way to diagnose PAH. According to the American and European clinical practice guidelines [4-6], the diagnosis involves sequences of steps and requires several invasive and noninvasive examinations. Well experienced specialists are needed to interpret the results and manage these patients $[7,8]$. Thus, sensitive and specific biomarkers of PAH are highly desirable to aid in the screening, diagnosis, and follow-up.

Previous studies have suggested that atrial natriuretic peptide (ANP), N-terminal probrain natriuretic peptide (NTproBNP), troponin, and uric acid are potential biomarkers for PAH [9-12]. However, these are not specific biomarkers of the pathology changed of the pulmonary artery hypertension. Endothelial cell dysfunction, proliferation without apoptosis, and vasoconstriction may play important roles in $\mathrm{PAH}$; therefore vascular bed may be a good source of new biomarkers [13-15]. 
Caveolae are $50-100 \mathrm{~nm}$ vesicular invaginations of the cell plasma membrane and caveolin-1 (Cav1) is the structural protein of caveolae and is highly expressed in adipocytes, endothelial cells, and type I pneumocytes. $\mathrm{Cavl}^{-/-}$mice exhibit pulmonary hypertension and right ventricle hypertrophy [16-18]. In monocrotaline-induced $\mathrm{PH}$ rat models, Cavl deficiency is seen in lung tissue [19]. Lungs tissues from idiopathic PAH (IPAH) patients decreased expression of Cav1 in vascular endothelial cells and also decreased in the total lung lysate [20, 21]. Furthermore, Cav1 can be secreted into serum and be detected [22]. These results suggested that Cav1 may play an important role in the pathogenesis of PAH and serum Cavl level may be a good biomarker for diagnosis $[23,24]$.

\section{Materials and Methods}

In the study, age matched patients with normal left ventricle function were divided into 3 groups. In Group (1) IPAH patients $(n=21)$, definite diagnosis was made according to European Society of Cardiology (ECS) [4] and American Heart Association (AHA/ACC) [5] guideline, inclusion criteria including mean pulmonary artery pressure (mPAP) $\geq 25 \mathrm{mmHg}$, pulmonary wedge pressure less or equal to $15 \mathrm{mmHg}$, and pulmonary vascular resistance over 3 Wood units measured by right heart catheterization. In Group (2) chronic obstructive pulmonary disease with pulmonary hypertension (COPD-PH) patients $(n=22)$, COPD were diagnosed by pulmonologist and estimated mean PAP $\geq$ $25 \mathrm{mmHg}$ by echocardiography. Group (3) (non-PAH group) includes healthy volunteers $(N=26)$ with mPAP less than $15 \mathrm{mmHg}$ measured by echocardiography.

Demographic data and clinical features of patients included in this study were summarized in Table 1. According to Tahir et al. reports $[23,24]$, we developed a direct sandwich immunoassay for the determination serum Cav1 level from participants. Serum hsCRP, NT-proBNP, and BMPR2 levels were also measured by commercial ELISA kits. This study was approved by Local Ethical Committee in Taichung Veterans General Hospital, Taichung, Taiwan (number CE12022). Written informed consent was provided to all participants.

2.1. Protocol for Serum Cav1 Assay. Two commercial affinity purified monoclonal mouse Cavl antibodies and polyclonal rabbit Cavl antibodies were chosen for a direct sandwich ELISA. The capture Cavl antibody used was generated from human recombinant Cav1 (R\&D systems), and the detection antibody was HRP-conjugated rabbit polyclonal antibody raised against a peptide mapping at the $\mathrm{NH}_{2}$ terminus of human Cavl (Santa Cruz Biotechnology). Costar microplate wells were coated with $100 \mu \mathrm{L}$ of Cavl antibody $(2.5 \mathrm{mg} / \mathrm{L})$ in PBS ( $\mathrm{pH} 7.4$ ) and incubated overnight at $4^{\circ} \mathrm{C}$. The wells were then blocked with $300 \mu \mathrm{L}$ of PBS containing $0.5 \%$ BSA and $0.05 \% \mathrm{v} / \mathrm{v}$ Tween 20 for 2 hours at room temperature and were washed three times with PBS containing $0.5 \% \mathrm{v} / \mathrm{v}$ Tween 20 (PBST). Serum samples, calibrators, and controls were added $(100 \mu \mathrm{L})$ to the wells and incubated overnight at $4^{\circ} \mathrm{C}$. The wells were washed three times with $400 \mu \mathrm{L}$ of PBST and $100 \mu \mathrm{L}$ of HRP-conjugated Cavl (Santa Cruz Biotechnology)

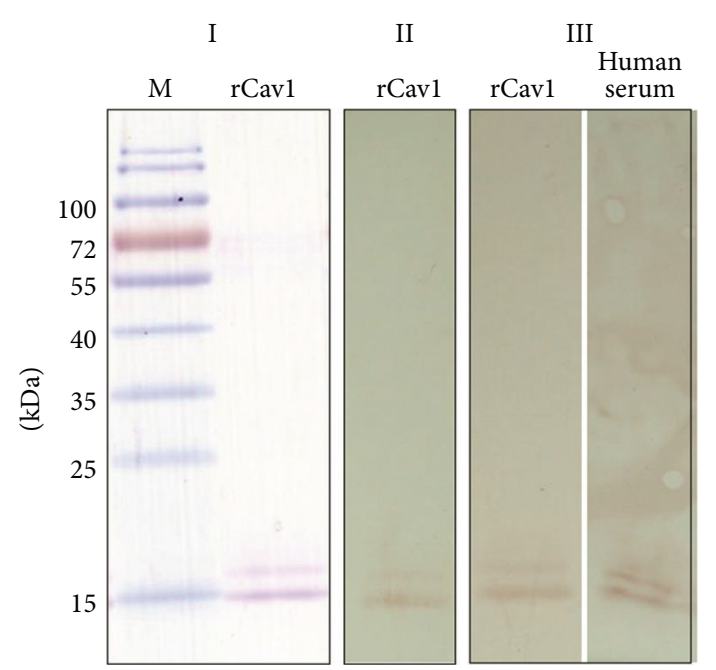

Figure 1: Specificity of capture and detection antibodies to rCav-1 and native Cavl of human serum. Recombinant Cavl protein was purified using affinity chromatography and analyzed by SDS-PAGE (I) and immunoblotting (II and III). In panel I, the rCav-1 protein migrated as a single band and displayed $>95 \%$ purity by Coomassie blue staining. The binding specificity of the capture and detection antibodies to rCav-1 and human serum was demonstrated and showed in panel II and panel III, respectively. Numbers on the left indicate sizes of protein markers (lane M).

antibody diluted 1:2000 in PBST. After incubation for $2 \mathrm{hr}$ at room temperature, the wells were washed three times with PBST, and $100 \mu \mathrm{L}$ of $3,3^{\prime}, 5,5^{\prime}$-tetramethylbenzidine substrate solution (Clinical Science Products, Inc.) was added and incubated for $30 \mathrm{~min}$ at room temperature. The reaction was stopped by adding $100 \mu \mathrm{L}$ of $1 \mathrm{~N} \mathrm{H}_{3} \mathrm{PO}_{4}$, and the absorbance was read at $450 \mathrm{~nm}$ with a microplate reader (TECAN, Grödig, Austria). Serum Cavl levels were measured using labmade recombinant pQE30-Cav 1 (a 101-amino acid region of Cavl gene from GenBank accession number NM001753) as a standard. A linear standard curve was constructed using a concentration range $(12.19-780 \mathrm{pg} / \mathrm{mL})$ of recombinant Cav1 in a parallel ELISA. The levels of Cav1 in sera of $21 \mathrm{IPAH}$ patients, 22 COPD-PH patients, and 26 healthy controls by the in-house ELISA were then measured. The limit of detection of the sandwich ELISA was $12.19 \mathrm{pg} / \mathrm{mL}$. Any value below the detective limitation of the assay referred to zero. In Figure 1, Western blot data using capture and detection antibodies that react to recombinant Cavl proteins was showed.

2.2. Enzyme-Linked Immunosorbent Assay for HsCRP, NTproBNP, and BMPR2 Detection. The serum levels of highsensitivity C-reactive protein (hsCRP), NT-proBNP, and bone morphogenetic protein type II receptor (BMPR2) were measured with enzyme-linked immunosorbent assay (ELISA) kits, hsCRP (Cell Biolabs, Inc., San Diego, CA), NT-proBNP (Invitrogen Corporation, Camarillo, CA), and BMPR2 (MyBioSource, San Diego, CA) according to the manual. 


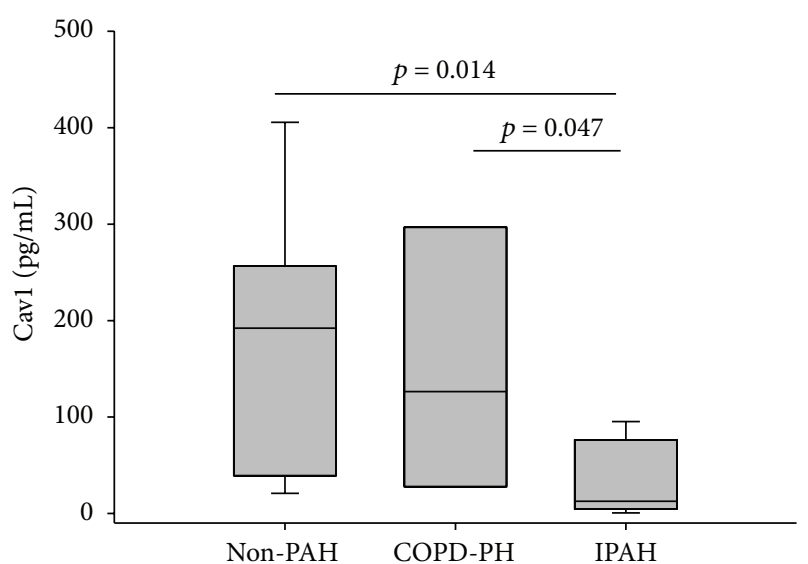

(a)

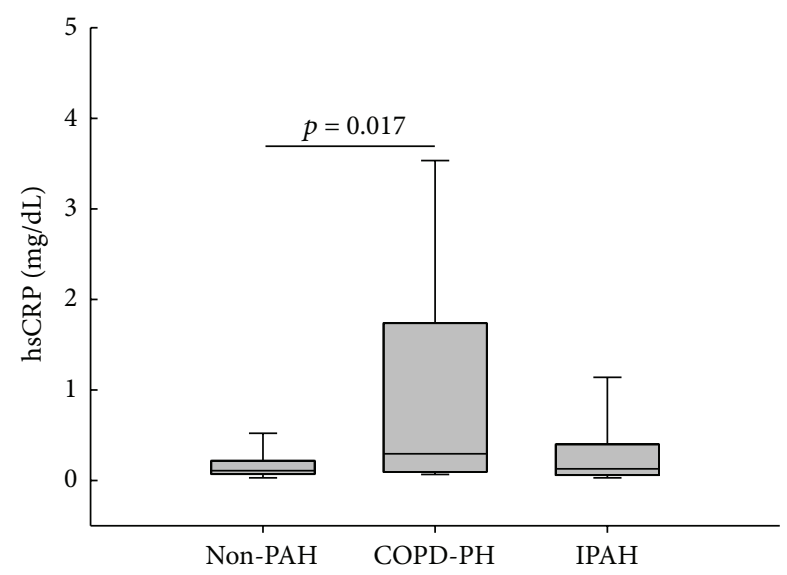

(c)

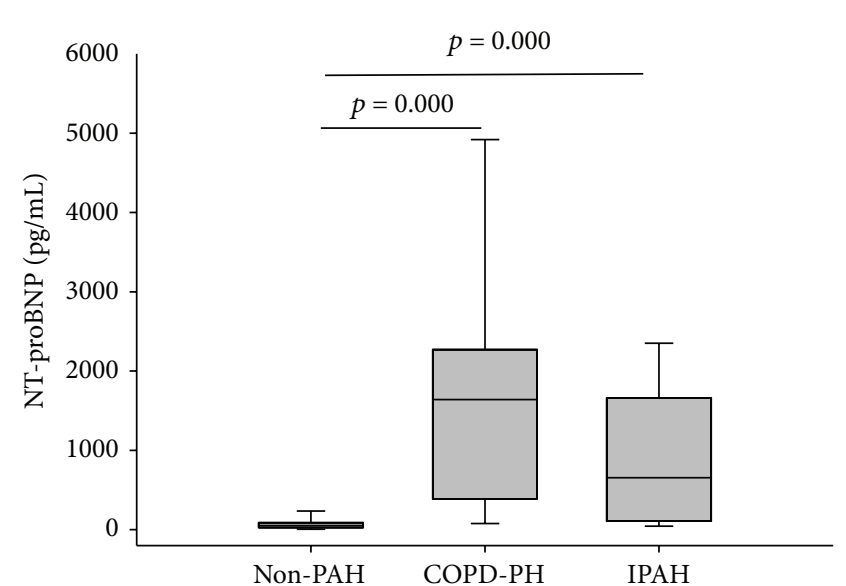

(b)

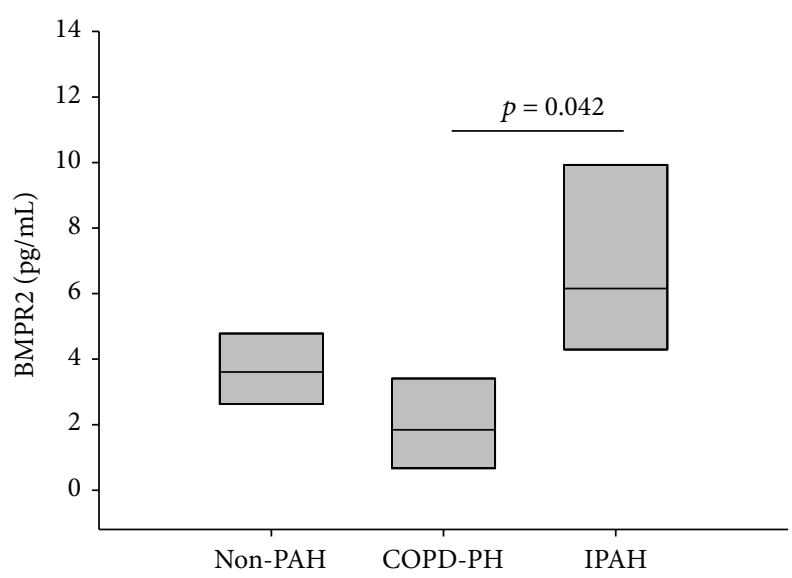

(d)

FIGURE 2: Serum biomarker levels in PAH patients and control subjects. PAH: pulmonary artery hypertension, COPD-PH: chronic obstructive pulmonary disease with pulmonary hypertension, and IPAH: idiopathic PAH.

2.3. Statistical Analysis. All data were expressed as mean \pm standard deviation. One-way analysis of variance (ANOVA) was used to compare continuous variables among different groups and Mann-Whitney $U$ test was used to compare variables between groups. Optimal thresholds for survival analysis were identified using Receiver-Operated Characteristics (ROC) analysis. Statistical analysis was performed using SPSS 18 (SPSS; Chicago, IL, USA).

\section{Results}

In Table 1, patients in IPAH group were younger than nonPAH volunteer and COPD-PH group, but not significant $(p=$ $0.16)$. There were more female patients $(n=14)$ than male patients $(n=6)$ in IPAH group. The systolic blood pressure was significantly lower than IPAH groups, which may result from right heart failure $(p=0.002)$. The PA pressure was significantly different between IPAH, COPD-PH, and nonPAH group $(p<0.005)$.

In Figure 2(a), serum Cavl level was significantly low in IPAH compared to non-PAH and COPD-PH group (76.45 \pm
32.41 versus $140.75 \pm 59.72 \mathrm{pg} / \mathrm{mL}$ and $173.57 \pm 42.75 \mathrm{pg} / \mathrm{mL}$; $p=0.014$ and $p=0.047)$. But there was no significant difference between non-PAH and COPD-PH. NT-proBNP (Figure 2(b)) was significantly higher in IPAH and COPD$\mathrm{PH}$ than normal group $(933.59 \pm 210.09$ and $1806.38 \pm 474.07$ versus $83.436 \pm 22.33 \mathrm{pg} / \mathrm{mL}$, both $p<0.05)$, but there is no difference between IPAH and COPD-PH groups. hsCRP (Figure 2(c)) was significantly higher in COPD-PH group than non-PAH group $(1.02 \pm 0.32$ versus $0.20 \pm 0.04 \mathrm{mg} / \mathrm{mL}$, $p=0.017)$, but there is no difference between COPD-PH and IPAH group $(1.02 \pm 0.32$ versus $0.37 \pm 0.15 \mathrm{mg} / \mathrm{mL}, p>0.5)$. BMPR2 (Figure 2(d)) was higher in IPAH group than COPD$\mathrm{PH}$ group $(22.35 \pm 15.60$ versus $2.57 \pm 0.99 \mathrm{pg} / \mathrm{mL}, p=0.019)$, but there is no significant difference between COPD-PH and non-PAH group $(2.57 \pm 0.99$ versus $6.41 \pm 3.27 \mathrm{pg} / \mathrm{mL}, p>$ $0.5)$.

In IPAH patients, using serum Cavl, $17.17 \mathrm{pg} / \mathrm{mL}$ as a cutoff value (Table 2 ), the sensitivity was 0.59 , the specificity was 1.0, and area under ROC curve was 0.816 (Figure 3(a)). Using NT-proBNP, $89.25 \mathrm{pg} / \mathrm{mL}$ as a cutoff value, the sensitivity was 0.889 , the specificity was 0.778 , and area under 
TABLE 1: Demographic data patients with pulmonary artery hypertension and healthy controls.

\begin{tabular}{|c|c|c|c|c|}
\hline & Non-PAH $(n=27)$ & COPD-PH $(n=20)$ & IPAH $(n=20)$ & $p$ value \\
\hline Age, yrs & $51.30 \pm 11.71(64-38)$ & $58.9 \pm 12.96(75-39)$ & $45.4 \pm 16.16(78-18)$ & 0.16 \\
\hline Sex (male/female) & $22 / 5$ & $16 / 4$ & $6 / 14$ & 0.000 \\
\hline Height, cm & $161.94 \pm 6.84(182-152)$ & $160.63 \pm 7.22(169.5-144)$ & $158.93 \pm 7.53(176-147)$ & 0.366 \\
\hline Weight, kg & $66.65 \pm 12.31(86.5-49.5)$ & $67.28 \pm 12.50(94-46)$ & $63.51 \pm 13.43(98-46)$ & 0.578 \\
\hline BMI, $\mathrm{kg} / \mathrm{m}^{2}$ & $25.45 \pm 3.91(33.76-18.29)$ & $16.16 \pm 5.10(38.58-17.10)$ & $25.15 \pm 5.64(42.7-18.36)$ & 0.791 \\
\hline History of DM & $5(18.5 \%)$ & $5(25.0 \%)$ & $0(0)$ & 0.68 \\
\hline History of HTN & $8(29.6 \%)$ & $10(45.5 \%)$ & $4(18.2 \%)$ & 0.117 \\
\hline PAP peak (mmHg) & $17.69 \pm 4.48(8-25.8)$ & $46.76 \pm 12.74(35-72.6)$ & $96.37 \pm 30.76(47.30-169)$ & 0.000 \\
\hline PAP mean (mmHg) & $12.36 \pm 2.89(6.3-18.80)$ & $31.14 \pm 7.93(23.4-48.4)$ & $57.79 \pm 14.87(29.60-84.5)$ & 0.000 \\
\hline SBP, mmHg & $133.35 \pm 16.01(170-104)$ & $132.80 \pm 22.24(176-96)$ & $113.20 \pm 23.10(175-86)$ & 0.002 \\
\hline DBP, $\mathrm{mmHg}$ & $79.77 \pm 9.60(101-60)$ & $81.80 \pm 16.87(119-62)$ & $77.80 \pm 16.87(128-54)$ & 0.683 \\
\hline $\mathrm{TC}, \mathrm{mg} / \mathrm{dL}$ & $176.88 \pm 35.35(236-92)$ & $183.35 \pm 44.46(281-105)$ & $146.25 \pm 33.39(188-103)$ & 0.078 \\
\hline HDL_C, mg/dL & $41.6 \pm 9.31(59-29)$ & $48.8 \pm 38.5(166-6)$ & $52.4 \pm 14.84(66-33)$ & 0.753 \\
\hline $\mathrm{TG}, \mathrm{mg} / \mathrm{dL}$ & $142.88 \pm 69.20(373-53)$ & $127.50 \pm 94.72(458-23)$ & $79.88 \pm 33.28(148-38)$ & 0.139 \\
\hline Creatinine, $\mathrm{mg} / \mathrm{dL}$ & $1.08 \pm 0.27(2-0.7)$ & $1.44 \pm 0.75(4.4-0.8)$ & $0.88 \pm 1.6(1.2-0.6)$ & 0.515 \\
\hline AC_sugar, mg/dL & $108.23 \pm 26.36(177-79)$ & $110.50 \pm 42.04(235-49)$ & $108.75 \pm 34.78(189-83)$ & 0.980 \\
\hline Caveolin-1 pg/mL & $173.57 \pm 135.18(47.22-409.44)$ & $163.04 \pm 146.59(56.61-425.54)$ & $33.81 \pm 36.3(18-235)$ & 0.029 \\
\hline hsCRP mg/dL & $0.18 \pm 0.23(0.1-0.95)$ & $1.02 \pm 1.30(0.13-4.38)$ & $0.37 \pm 0.62(0.03-2.75)$ & 0.007 \\
\hline NT-proBNP pg/mL & $59.83 \pm 64.84(4.0-336)$ & $1426 \pm 1231(140-2790)$ & $933.6 \pm 891.3(107-2120)$ & 0.004 \\
\hline
\end{tabular}

PAH: pulmonary artery hypertension, COPD-PH: chronic obstructive pulmonary disease with pulmonary hypertension, IPAH: idiopathic PAH, PAP: pulmonary artery pressure, SBP: systolic blood pressure, DBP: diastolic blood pressure, hsCRP: high-sensitivity C-reactive protein, and NT-proBNP: Nterminal of the prohormone brain natriuretic peptide.

TABLE 2: Sensitivity and specificity data for cutoff point of Cavl and other biomarkers in IPAH patients.

\begin{tabular}{lccc}
\hline Biomarker & Cutoff value & Sensitivity & Specificity \\
\hline Cav1 & $17.17 \mathrm{pg} / \mathrm{mL}$ & 0.588 & 1 \\
NT-proBNP & $89.25 \mathrm{pg} / \mathrm{mL}$ & 0.889 & 0.778 \\
hsCRP & $0.27 \mathrm{mg} / \mathrm{dL}$ & 0.389 & 0.852 \\
BMPR2 & $3.71 \mathrm{pg} / \mathrm{mL}$ & 1 & 0.429 \\
\hline
\end{tabular}

ROC curve was 0.89 (Figure 3(b)). Using hsCRP, $0.27 \mathrm{mg} / \mathrm{dL}$ as a cutoff value, the sensitivity was 0.39 , the specificity was 0.85 , and area under ROC curve was 0.89 (Figure 3(c)). Using BMPR2, $3.71 \mathrm{pg} / \mathrm{mL}$ as a cutoff value, the sensitivity was 1.00 , the specificity was 0.43 , and area under ROC curve was 0.78 (Figure 3(d)). Linear regression analysis between Cavl and 6 min walk test, PAP, and PVR was done but did not show good correlation. Data were not shown here.

\section{Discussion}

There were two major findings in our results. First, serum Cavl might be a novel biomarker in the diagnosis of IPAH with fare sensitivity and good specificity. Second, Cav1 might be used to make differential diagnosis between COPD-PH and IPAH group.
Cavl was highly expressed in vascular endothelial cells but less in smooth muscle cells. The expression of Cav1 was decreased in the plexiform lesion from IAPH patients' lung tissue [20]. The expression in the smooth muscle cell was increased and immunoblotting from whole lung prepared revealed decreased expression of Cav1 $[25,26]$. In this study, we further demonstrate that the serum Cavl level in IPAH patients was also decreased (Figure 2(a)), and the difference was significant between IPAH, COPD-PH, and normal subjects. By using serum Cav1 level $17.17 \mathrm{pg} / \mathrm{mL}$ as cutoff value in the diagnosis of IPAH, there were fare sensitivity (0.6) and good specificity (1.0) (Figure 3(a)).

In a small number of COPD with $\mathrm{PH}$ patients (mean PAP: $29.5 \pm 5.1 \mathrm{mmHg}$ ), the intimal expression of Cavl was decreased as compared with COPD patients without $\mathrm{PAH}$ (mean PAP: $16.7 \pm 2.7 \mathrm{mmHg}$ ) [27]. Our data did not show significant difference between COPD-PH and normal subjects, but there was significant difference between COPD$\mathrm{PH}$ and IPAH patients (Figure 2(a), $p=0.047$ ). Although smooth muscle proliferation with increasing Cavl expression was noted in both COPD-PH and IPAH patients, our results suggested the serum Cav1 level correlated with its expression in endothelial cells but not the smooth muscle cells. Our data suggest that Cav1 may be potential biomarkers for elevated $\mathrm{PA}$ pressure and could be used for differential diagnosis of COPD-PH and IPAH. 


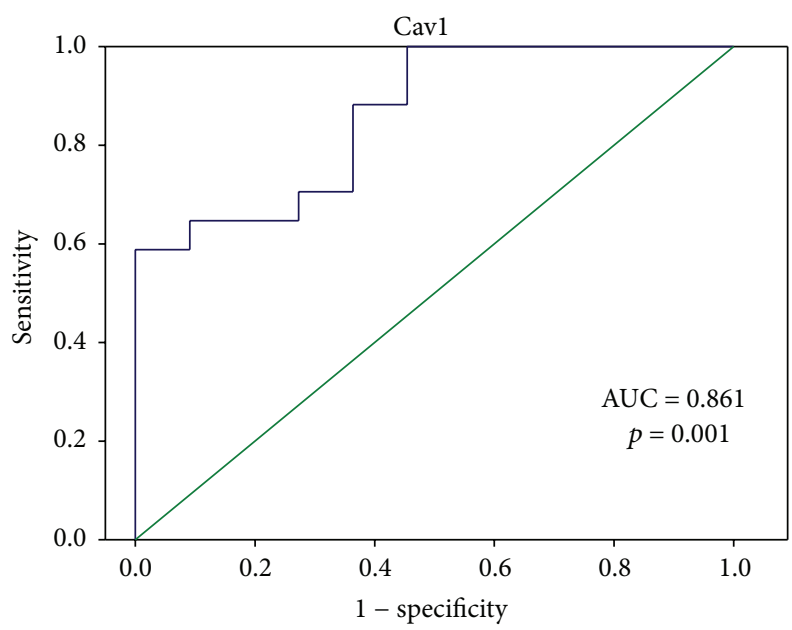

(a)

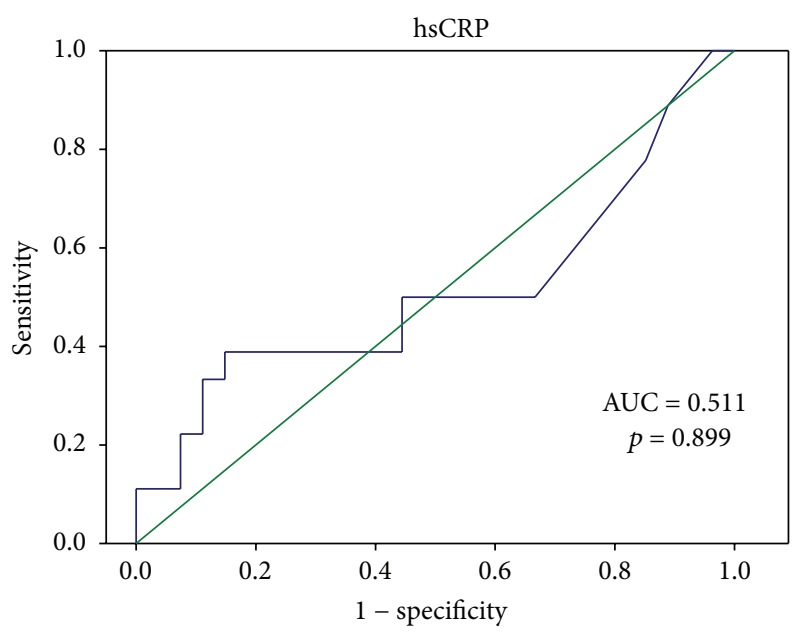

(c)

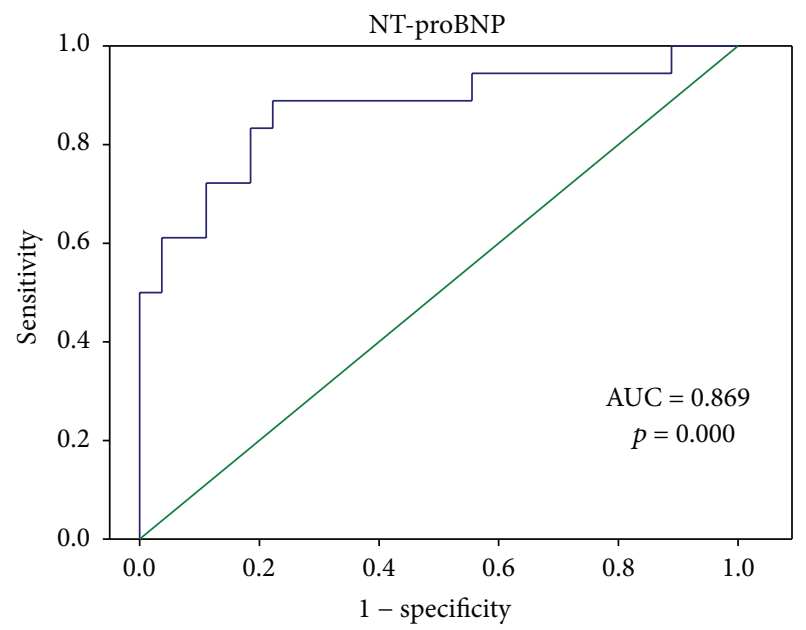

(b)

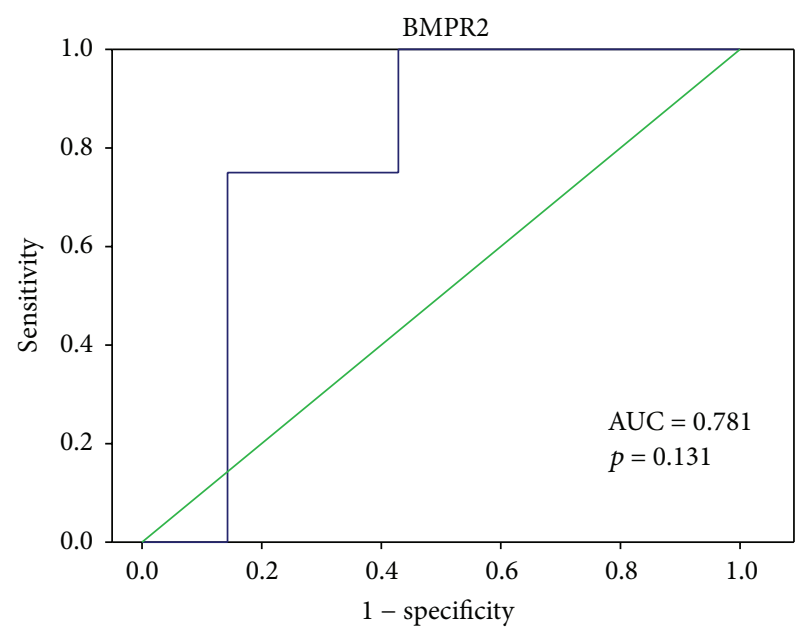

(d)

FIGURE 3: Receiver operator curve analysis of Cavl and other biomarkers in idiopathic pulmonary artery hypertension (IPAH) patients.

NT-proBNP is secreted by the ventricles of the heart in response to excessive stretching of cardiomyocytes. Serum NT-proBNP elevated in both left and right ventricle dysfunction $[28,29]$. In COPD patients with $\mathrm{PAH}$ and right heart failure, the NT-proBNP was also elevated [30]. In our results (Figure 2(b)), NT-proBNP levels were significantly higher in both COPD-PAH and IPAH groups than normal subjects, but there was no significant difference between the disease subjects. hsCRP, a nonspecific biomarker in response to different pathogenesis of inflammation, was higher in COPD patients due to chronic lung inflammation (Figure 2(c), $p=0.017$ ) than normal group. But there was no difference between COPD-PH and IPAH groups. Mutations in the BMPR2 gene resulted in the development of familial primary pulmonary hypertension, but the role BMPR2 mutations play in the development of PH has not been clarified. Cav1 and BMPR2 were colocalized in both endothelial and smooth muscle cell membrane [31,32] and Cavl was suggested to regulate
BMPR2 downstream signaling. In this study (Figure 2(d)), serum BMPR2 level was not significantly different between normal subjects versus IPHA patients and normal subjects versus COPD-PAH patients. But the differences between IPAH and COPD with PAH were significantly different $(p=$ 0.019 ). Further study may be indicated to elucidate the relation between Cavl and BMPR2 in IPAH patients.

Taken together, our results demonstrated that reduced serum Cavl level may be a potential biomarker in IPAH diagnosis and could be used for differential diagnosis of pulmonary artery hypertension patients between idiopathic pulmonary hypertension and COPD.

\section{Study Limitation}

This is a small number cross-sectional study. COPD-PH is more frequent in males; IPAH is more frequent in females. It is difficult to correct the match number of patients in gender. 
The IPAH patients included were at different treatment status, including newly diagnosed IPAH without medication to double or even triple drugs combined therapy. The functional status of heart failure may also influence Cavl serum level. Therefore, we find only poor correlation between Cav1 level and pulmonary artery pressure, pulmonary vascular resistance, and 6-minute wall test. However, our results suggested serum Cav1 level might be used as an easy and convenient way for IAPH initial diagnosis. Future studies are necessary to include more patients at different stages of disease, to evaluate Cavl level in response to different treatment, to predict the IPAH progression and long-term prognosis.

\section{Conflict of Interests}

The authors declare that there is no conflict of interests regarding the publication of this paper.

\section{Acknowledgments}

This research was support by Grant nos. TCVGH-1013104B, TCVGH-1033101A from the Taichung Veterans General Hospital and Taichung Veterans General Hospital/Tunghai University Joint Research Program (TCVGH-T1037802).

\section{References}

[1] A. J. Peacock, "Treatment of pulmonary hypertension," British Medical Journal, vol. 326, no. 7394, pp. 835-836, 2003.

[2] G. E. D’Alonzo, R. J. Barst, S. M. Ayres et al., "Survival in patients with primary pulmonary hypertension: results from a national prospective registry," Annals of Internal Medicine, vol. 115, no. 5, pp. 343-349, 1991.

[3] D. B. Badesch, G. E. Raskob, C. G. Elliott et al., "Pulmonary arterial hypertension: baseline characteristics from the REVEAL registry," Chest, vol. 137, no. 2, pp. 376-387, 2010.

[4] N. Galiè, M. M. Hoeper, M. Humbert et al., "Guidelines for the diagnosis and treatment of pulmonary hypertension," European Heart Journal, vol. 30, pp. 2493-2537, 2009.

[5] V. V. McLaughlin, S. L. Archer, D. B. Badesch et al., "ACCF/AHA 2009 expert consensus document on pulmonary hypertension: a report of the American College of Cardiology Foundation Task Force on Expert Consensus Documents and the American Heart Association: developed in collaboration with the American College of Chest Physicians, American Thoracic Society, Inc., and the Pulmonary Hypertension Association," Circulation, vol. 119, pp. 2250-2294, 2009.

[6] M. D. McGoon, R. L. Benza, P. Escribano-Subias et al., "Pulmonary arterial hypertension: epidemiology and registries," Journal of the American College of Cardiology, vol. 62, no. 25, supplement, pp. D51-D59, 2013.

[7] G. Habib and A. Torbicki, "The role of echocardiography in the diagnosis and management of patients with pulmonary hypertension," European Respiratory Review, vol. 19, no. 118, pp. 288-299, 2010.

[8] D. B. Badesch, H. C. Champion, M. A. Gomez Sanchez et al., "Diagnosis and assessment of pulmonary arterial hypertension," Journal of the American College of Cardiology, vol. 54, no. 1, pp. S55-S66, 2009.
[9] N. Nagaya, T. Nishikimi, M. Uematsu et al., "Plasma brain natriuretic peptide as a prognostic indicator in patients with primary pulmonary hypertension," Circulation, vol. 102, no. 8, pp. 865870, 2000.

[10] N. Nagaya, M. Uematsu, T. Satoh et al., "Serum uric acid levels correlate with the severity and the mortality of primary pulmonary hypertension," American Journal of Respiratory and Critical Care Medicine, vol. 160, no. 2, pp. 487-492, 1999.

[11] J.-L. Cracowski and H. H. Leuchte, "The potential of biomarkers in pulmonary arterial hypertension," The American Journal of Cardiology, vol. 110, no. 6, pp. S32-S38, 2012.

[12] S. Rafeq, A. M. Shah, and I. R. Preston, "Biomarkers in pulmonary arterial hypertension," International Journal of Clinical Practice, vol. 63, no. 162, pp. 36-41, 2009.

[13] M. Humbert, N. W. Morrell, S. L. Archer et al., "Cellular and molecular pathobiology of pulmonary arterial hypertension," Journal of the American College of Cardiology, vol. 43, no. 12, supplement, pp. 13S-24S, 2004.

[14] S. Sakao, K. Tatsumi, and N. F. Voelkel, "Endothelial cells and pulmonary arterial hypertension: apoptosis, proliferation, interaction and transdifferentiation," Respiratory Research, vol. 10, article 95, 2009.

[15] M. R. Wilkins, "Pulmonary hypertension: the science behind the disease spectrum," European Respiratory Review, vol. 21, no. 123, pp. 19-26, 2012.

[16] M. Drab, P. Verkade, M. Elger et al., "Loss of caveolae, vascular dysfunction, and pulmonary defects in caveolin-1 genedisrupted mice," Science, vol. 293, no. 5539, pp. 2449-2452, 2001.

[17] L. A. Carver and J. E. Schnitzer, "Caveolae: mining little caves for new cancer targets," Nature Reviews Cancer, vol. 3, no. 8, pp. 571-581, 2003.

[18] Y.-Y. Zhao, Y. Liu, R.-V. Stan et al., "Defects in caveolin-1 cause dilated cardiomyopathy and pulmonary hypertension in knockout mice," Proceedings of the National Academy of Sciences of the United States of America, vol. 99, no. 17, pp. 11375-11380, 2002.

[19] J.-F. Jasmin, I. Mercier, J. Dupuis, H. B. Tanowitz, and M. P. Lisanti, "Short-term administration of a cell-permeable caveolin-1 peptide prevents the development of monocrotalineinduced pulmonary hypertension and right ventricular hypertrophy," Circulation, vol. 114, no. 9, pp. 912-920, 2006.

[20] R. O. D. Achcar, Y. Demura, P. R. Rai et al., "Loss of caveolin and heme oxygenase expression in severe pulmonary hypertension," Chest, vol. 129, no. 3, pp. 696-705, 2006.

[21] Y.-Y. Zhao, Y. D. Zhao, M. K. Mirza et al., "Persistent eNOS activation secondary to caveolin-1 deficiency induces pulmonary hypertension in mice and humans through PKG nitration," Journal of Clinical Investigation, vol. 119, no. 7, pp. 2009-2018, 2009.

[22] P. Liu, W.-P. Li, T. Machleidt, and R. G. W. Anderson, "Identification of caveolin-1 in lipoprotein particles secreted by exocrine cells," Nature Cell Biology, vol. 1, no. 6, pp. 369-375, 1999.

[23] S. A. Tahir, S. Kurosaka, R. Tanimoto, A. A. Goltsov, S. Park, and T. C. Thompson, "Serum caveolin-1, a biomarker of drug response and therapeutic target in prostate cancer models," Cancer Biology and Therapy, vol. 14, no. 2, pp. 117-126, 2013.

[24] S. A. Tahir, C. Ren, T. L. Timme et al., "Development of an immunoassay for serum caveolin-1: a novel biomarker for prostate cancer," Clinical Cancer Research, vol. 9, part 1, no. 10, pp. 3653-3659, 2003. 
[25] H. H. Patel, S. Zhang, F. Murray et al., "Increased smooth muscle cell expression of caveolin-1 and caveolae contribute to the pathophysiology of idiopathic pulmonary arterial hypertension," The FASEB Journal, vol. 21, no. 11, pp. 2970-2979, 2007.

[26] R. Mathew, "Cell-specific dual role of caveolin-1 in pulmonary hypertension," Pulmonary Medicine, vol. 2011, Article ID 573432, 12 pages, 2011.

[27] L. C. Huber, A. Soltermann, M. Fischler et al., "Caveolin-1 expression and hemodynamics in COPD patients," Open Respiratory Medicine Journal, vol. 3, pp. 73-78, 2009.

[28] J. L. Januzzi Jr., S. U. Rehman, A. A. Mohammed et al., "Use of amino-terminal pro-B-type natriuretic peptide to guide outpatient therapy of patients with chronic left ventricular systolic dysfunction," Journal of the American College of Cardiology, vol. 58, no. 18, pp. 1881-1889, 2011.

[29] N. Nagaya, T. Nishikimi, Y. Okano et al., "Plasma brain natriuretic peptide levels increase in proportion to the extent of right ventricular dysfunction in pulmonary hypertension," Journal of the American College of Cardiology, vol. 31, no. 1, pp. 202-208, 1998.

[30] S. Y. Chi, E. Y. Kim, H. J. Ban et al., "Plasma N-terminal probrain natriuretic peptide: a prognostic marker in patients with chronic obstructive pulmonary disease," Lung, vol. 190, no. 3, pp. 271-276, 2012.

[31] J. W. Wertz and P. M. Bauer, "Caveolin-1 regulates BMPRII localization and signaling in vascular smooth muscle cells," Biochemical and Biophysical Research Communications, vol. 375, no. 4, pp. 557-561, 2008.

[32] M. Ramos, M. W. Lamé, H. J. Segall, and D. W. Wilson, “The BMP type II receptor is located in lipid rafts, including caveolae, of pulmonary endothelium in vivo and in vitro," Vascular Pharmacology, vol. 44, no. 1, pp. 50-59, 2006. 


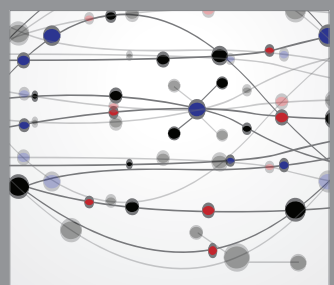

The Scientific World Journal
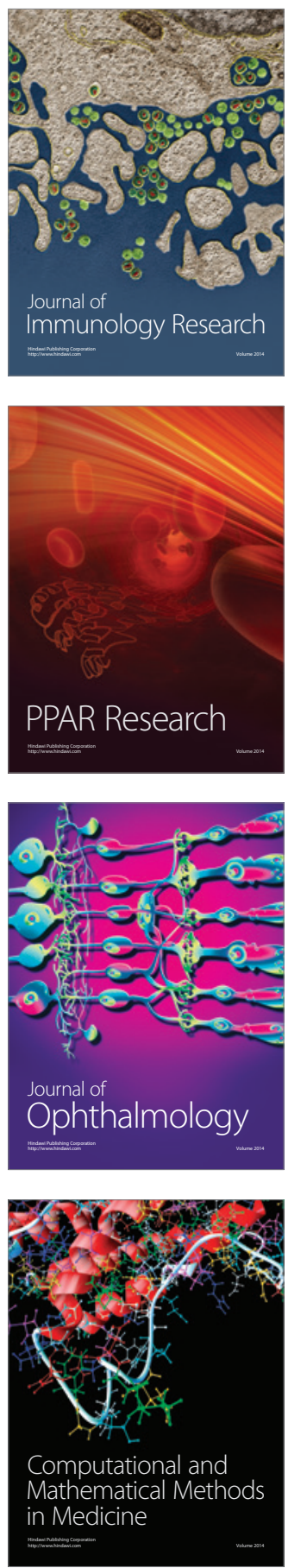

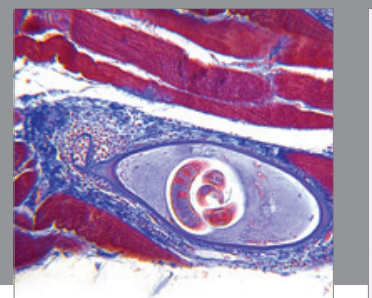

Gastroenterology

Research and Practice
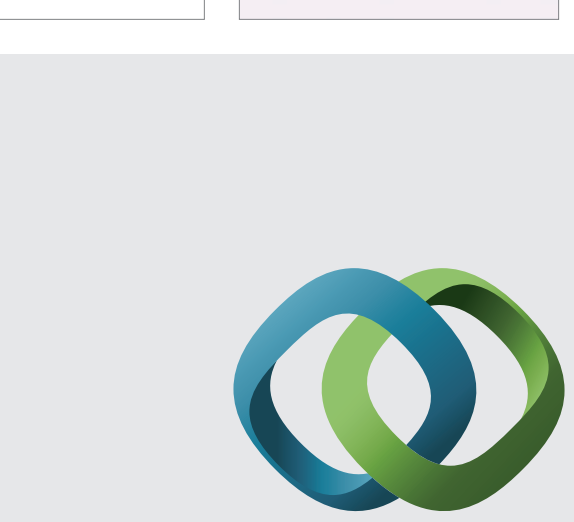

\section{Hindawi}

Submit your manuscripts at

http://www.hindawi.com
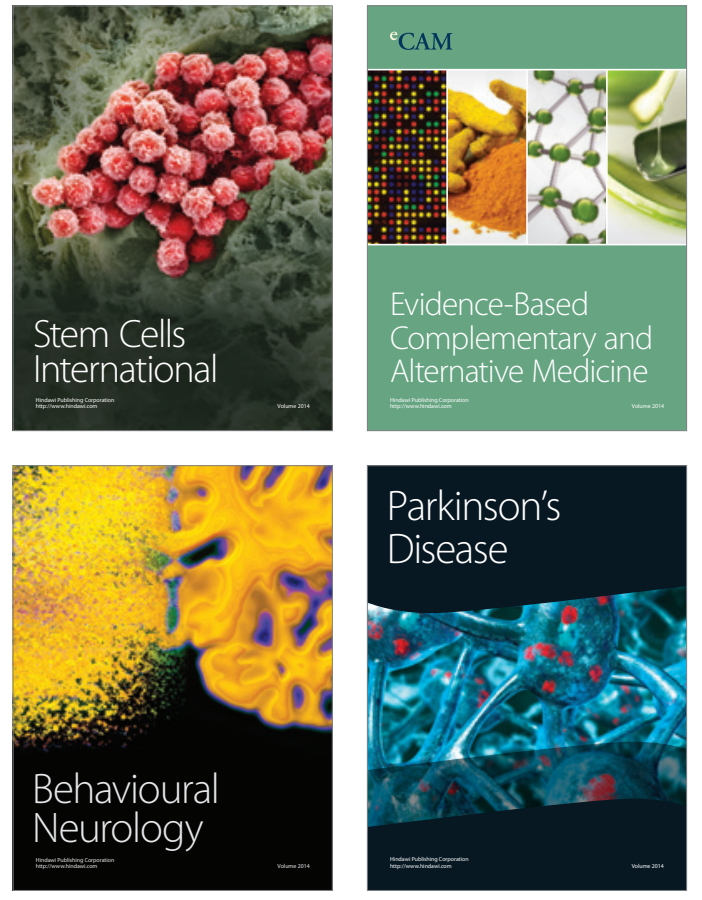
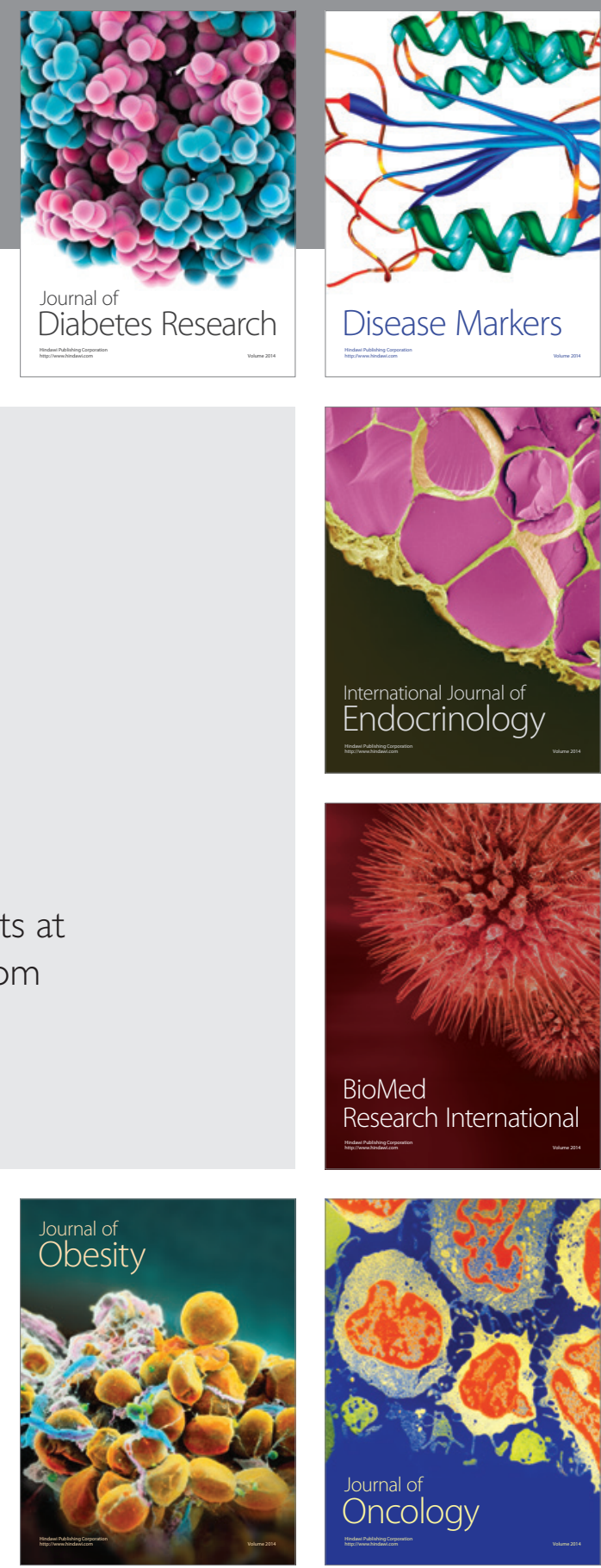

Disease Markers
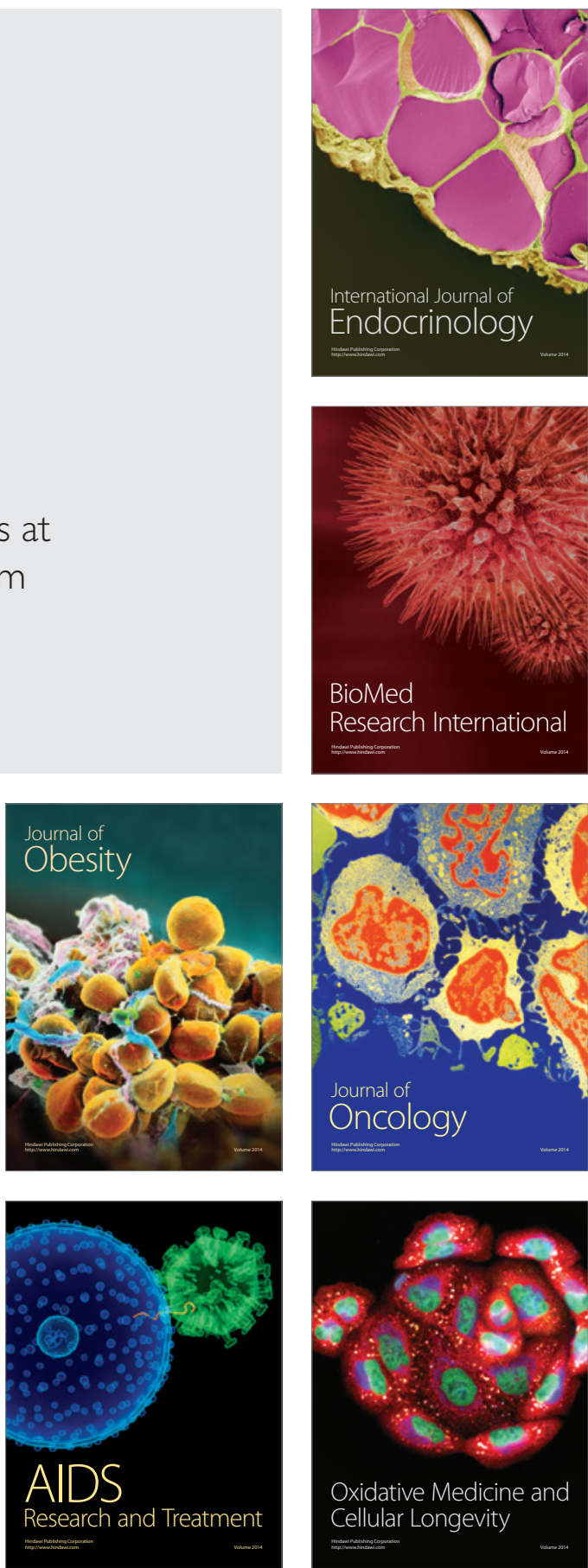